\title{
As ocupações das escolas públicas e a defesa da Sociologia no Ensino Médio
}

Carolina Simões Pacheco ${ }^{1}$

\author{
Kamille Brescansin Mattar ${ }^{2}$
}

\section{RESUMO}

O presente trabalho tem como tema central as reformas educacionais aprovadas em 2017 (MP 746 e PEC 55), em que a Sociologia deixa de ser obrigatória, e a consequente mobilização estudantil com a ocupação de centenas de escolas públicas no país. Nosso objetivo principal é propor uma reflexão, através da ênfase no movimento das ocupações, sobre a forma como os estudantes estão vivenciando e compreendendo as discussões sobre educação. Disso, surge o objetivo específico em debater qual é a finalidade potencial que a disciplina de Sociologia assume nesse processo, tanto a partir da perspectiva legislativa e histórica quanto da narrativa dos próprios estudantes dentro das ocupações. Diante disso, partimos nossa análise da implementação da Sociologia como um processo intermitente no Brasil, evidenciando a fragilidade da sua permanência na grade curricular; para em seguida, discutir qual a experiência escolar desses jovens enquanto estudantes e ocupantes. A hipótese aqui defendida é que essa experiência é negativa, e a retirada da obrigatoriedade da Sociologia reforça este processo. Por isso, a pergunta que nos norteia durante todo o trabalho é qual é a finalidade que a Sociologia pode e deve assumir neste contexto.

Palavras-chave: Ensino de Sociologia, juventude, participação política.

\footnotetext{
Doutoranda no Programa de Pós-graduação em Sociologia da Universidade Federal do Paraná, bolsista Capes, carolspg@gmail.com.

2 Mestranda no Programa de Pós-graduação em Sociologia da Universidade Federal do Paraná, bolsista Capes, mille.mattar@gmail.com.
} 
Este trabalho tem como temáticas centrais a reforma do ensino médio e a consequente mobilização dos estudantes secundaristas da rede pública, que culminou na ocupação de 86 escolas só em Curitiba ${ }^{3}, 850$ escolas no Estado do Paraná e um total de 1.071 em todo o Brasil ${ }^{4}$, (PACHECO, 2018), ficando conhecido como 'A primavera secundarista'.

Para tanto, em um primeiro momento, vamos nos deter em contextualizar a reforma escolar, buscando debater quais seus significados e sentidos possíveis, que para nós se apresentam como a precarização e a tecnicização do Ensino Médio público; e o lugar da Sociologia nesse processo, a qual vamos discutir a partir da defesa do papel crítico e reflexivo que disciplina pode e deve assumir neste momento. Em seguida, trabalharemos os movimentos das ocupações escolares ocorridos em 2016, trazendo como a noção de experiência aparece no desenvolvimento do estudante enquanto ator político, com base no proposto por Thompson (1981) e Honneth (2003).

Com isso, de forma expressa nosso objetivo principal é propor uma reflexão sobre como os estudantes estão vivenciando as discussões sobre educação, e quais suas compreensões sobre esses processos, inclusive no que se refere à finalidade da Sociologia como disciplina curricular obrigatória no Ensino Médio. A hipótese que pretendemos sustentar é que a Sociologia, no processo de legitimação da especificidade de um saber sociológico, deve assumir e reivindicar dentro da matriz curricular um lugar de compreensão reflexiva sobre as vivências juvenis, contribuindo para que os estudantes

\footnotetext{
3 Dados retirados do site do Movimento Ocupa Paraná: http://ocupaparana.org/

4 Incluindo Institutos Federais, campis de Universidades Federais e Estaduais e Núcleos Regionais de Educação.
} 
reflitam sobre sua condição de participação no cotidiano escolar enquanto atores sociais.

Isto posto, vale ressaltar que este trabalho é parte constituinte de projeto de mestrado e doutorado em desenvolvimento e resultado de pesquisa iniciada, e ainda em desenvolvimento, pelo sub-grupo Sociologia da Educação ${ }^{5}$, que compõe o Grupo de Pesquisa de Pensamento Social Brasileiro da UFPR sobre as ocupações escolares. Nesta pesquisa, o objetivo era compreender os sentidos e sentimentos em relação à ocupação dos estudantes que participaram do movimento. Para tanto, foram realizadas 03 entrevistas com o7 estudantes no total, cada uma com uma média de duas horas e meia de duração, todos de uma mesma escola estadual da cidade de Curitiba.

\section{$O$ contexto da reforma de ensino}

No que se refere aos direitos sociais e às responsabilidades estatais para a garantia destes, pode-se afirmar que a Constituição Federal de 1988 foi a consolidação de um processo de síntese de debates e disputas na sociedade, que inaugurou ações de ampliação da noção de cidadania no Brasil. No ano em que a Assembleia Constituinte completa trinta anos, no entanto, podemos olhar para este processo de forma reflexiva, identificando como as decisões subsequentes ao mesmo tempo em que corroboraram essa potencial ampliação de direitos sociais, também são marcadas por disputas em torno das decisões governamentais e na aplicação destas leis.

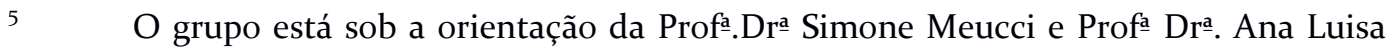
Sallas. Ainda integram o grupo: Alexandre Correia Lima, Brian Broguszewski, Ramiro Garcia, Sabrina Freitas, Tabata Soldan, Virginia Lourençon. 
A educação é o foco da presente análise, a qual tem como objetivo traçar um diálogo entre estas disposições legais, as decisões governamentais em torno de suas aplicações e a percepção dos estudantes secundaristas sobre a vivência do cotidiano escolar. O diagnóstico inicial é trazido pelos próprios secundaristas: a maior ocupação estudantil da história, com mais de mil instituições de ensino ocupadas contra a Medida Provisória 746 e contra a Proposta de Emenda Constitucional 241. Tentaremos demonstrar, ao longo deste trabalho, como as ocupações são narradas pelos estudantes como uma ferramenta de aplicação das garantias legais, que estabelecem a escola como um espaço formativo de cidadania. No entanto, as regulamentações em torno da educação não são uníssonas, como também evidenciaremos na sequência.

O Brasil tem um histórico recente de leis e diretrizes em relação à educação, que passou a ser considerada um direito social básico e responsabilidade do Estado justamente a partir da Constituição Federal, de 1988. No que tange o Ensino Médio, especificamente, a CF/88 trata da necessidade de ampliação desta etapa de ensino, bem como da necessidade de gratuidade da mesma (CF/88, Cap. 2. Dos Direitos Sociais. Art. 6o). A educação passa a ser dividida em básica (fundamental e médio) e superior com a Lei de Diretrizes e Bases, de 1996. A LDB rege ainda, a divisão de etapas em relação às esferas estatais, em que o Ensino Fundamental é considerado responsabilidade dos Municípios, o Ensino Médio dos Estados e o Ensino Superior, da União. Em 2009, a Lei no 12.061 trata especificamente da regulamentação do Ensino Médio e estabelece a necessidade de universalização desta etapa de ensino, bem como sua gratuidade.

Em 2014, há um avanço importante das regulamentações e normativas em relação à educação com a aprovação da Lei no 13.005/2014, que institui o Plano Nacional de Educação, estabelecendo metas em relação à ampliação 
do ensino no Brasil a serem cumpridas em um decênio. A Sociologia e a Filosofia passam a ser disciplinas obrigatórias para todas as séries do Ensino Médio em 2008, através da Lei $\mathrm{n}^{\circ}$ 11.684/o8. Este processo de regulamentação da educação foi construído pelo Ministério da Educação com participação de outros Ministérios (como o do Trabalho e de Ciência e Tecnologia) e Secretarias (como a da Juventude). Além disso, houve espaços de consulta da sociedade civil, como as Conferências (municipais, estaduais e nacionais), que trataram do tema. O processo de divulgação e implementação da Medida Provisória 746 pode ser considerado intransigente por não levar este histórico de debates e organização em conta.

Um primeiro demonstrativo da arbitrariedade desta proposta é em relação às metas de ampliação do Ensino Médio. O processo de universalização, até então considerado meta prioritária em relação ao Ensino Médio, foi substituído pela meta de ampliação do ensino integral. A proposta de Reforma do Ensino Médio foi anunciada em 2016 com o objetivo de reordenar esta etapa de ensino, tendo como objetivo central a ampliação da carga horária e a consolidação do ensino integral. A carga horária atual, de 880 horas anuais, deve ser ampliada para 1.400 horas anuais até 2021. A MP 746 trouxe como prioridade, ainda, uma reorganização curricular que insere as disciplinas, antes obrigatórias, como componentes, diluídos nas Áreas de Conhecimento, com a justificativa da interdisciplinaridade, do protagonismo e autonomia estudantil. As mudanças propostas pela MP 746 foram instituídas com Lei n. 13.415, aprovada em fevereiro de 2017.

A Base Nacional Comum Curricular (BNCC), aprovada em dezembro de 2017 e divulgada em março de 2018, orienta a implementação das mudanças propostas pela Lei n. 13.415/2017. As disciplinas de Língua Portuguesa, Língua Estrangeira, Educação Artística e Educação Física passam a compor, 
assim, a Área de Linguagens e suas Tecnologias; a disciplina de Matemática passa a ser considerada a Área de Matemática e suas Tecnologias; as disciplinas de Biologia, Física e Química passam a compor a Área de Ciências da Natureza e suas Tecnologias; as disciplinas de História, Geografia, Sociologia e Filosofia passam a compor a Área de Ciências Humanas e Sociais Aplicadas. Nestas áreas são definidos temas de estudo obrigatórios compostos de maneira interdisciplinar que podem ser aplicados sem o critério seriado. As habilidades de Linguagens e Matemáticas seguem como obrigatórias para todos os anos do Ensino Médio. No entanto, não são todos os componentes das Áreas de Linguagens que seguem obrigatórios. A Educação Artística, Educação Física e Língua Estrangeira deixam de ser obrigatórios em todas as séries do Ensino Médio e passam a ser considerados componentes da Área, que podem ser ensinados de forma interdisciplinar, inclusive pelo mesmo profissional habilitado para o ensino de língua portuguesa.

Este processo de reorganização acaba com a obrigatoriedade da formação específica, uma vez que não é mais necessário ser licenciado em Educação Física ou Educação Artística, mas somente em Língua Portuguesa. Além disso, restringe a obrigatoriedade do ensino de línguas estrangeiras, que antes poderia ser inglês ou espanhol. Em Ciências Humanas e Sociais Aplicadas há, portanto, componentes (História, Geografia, Sociologia e Filosofia) que podem ser diluídos no ensino de forma interdisciplinar, durante os três anos desta etapa. Alguns temas passam a ser considerados norteadores desta Área: tempo e o espaço; território e fronteira; indivíduo, natureza, sociedade, cultura e ética; política e trabalho. Na Área de CHSA são estabelecidos, ainda, seis competências específicas e cada uma delas traz uma série de subtópicos, com habilidades a serem desenvolvidas. As escolas que ofertam o Ensino Médio não são obrigadas a ofertar todas as Áreas, uma vez que esta passa a estar condicionada à existência de profissionais 
capacitados para ministrar as áreas, bem como pela demanda dos estudantes, que passam a optar e não mais ter todas elas como componentes básicos do currículo.

Além disso, o Conselho Nacional de Educação lançou este ano uma proposta de alteração das Diretrizes Nacionais Curriculares do Ensino Médio, em que 40\% do Ensino Médio poderá ser feito à distância, podendo chegar a $100 \%$ deste, para a Educação de Jovens e Adultos. Esta proposta evidencia como a justificativa inicial de ampliação da educação integral não parece ser, de fato, a maior demanda em relação ao Ensino Médio. Podemos avaliar ainda a MP 746 e esta proposta de ampliação do ensino à distância como formas de precarização do Ensino Médio, uma vez que rompem com a necessidade de profissionais habilitados para o ensino de conhecimentos específicos com a justificativa da interdisciplinaridade e da autonomia dos estudantes.

\section{Os caminhos e sentidos da Sociologia no ensino brasileiro}

A Sociologia, juntamente com a filosofia, assume um percurso emblemático nas reformas de ensino no Brasil, sendo marcada tanto pela intermitência da disciplina no currículo escolar quanto por sua origem ser atrelada à realidade escolar antes de ser direcionada à formação específica de cientistas sociais (COSTA, 2011). Essas duas condições moldam a compreensão ou a ausência de consolidação de uma finalidade própria do ensino da Sociologia no Ensino Médio, e talvez da própria instabilidade da disciplina.

As primeiras tentativas em instituir o debate sobre o ensino de Sociologia, com o Decreto Rui Barbosa seguido da Reforma Benjamin Constant (1890), foram moldadas por um caráter elitista, tendo em vista que apenas um 
grupo seleto de estudantes tinha acesso à disciplina, mais especificamente, aqueles que pretendiam ingressar nos cursos superiores de Medicina, Odontologia, Farmácia, Engenharia, Arquitetura e Direito. (GUELFI, 2001, apud OLIVEIRA, 2013). Em seguida, a obrigatoriedade da disciplina no início do século XX, com a Reforma Rocha Vaz (1925) seguida da Reforma Francisco Campos (1931), é alcançada em virtude de a percepção da época atrelar a Sociologia a um instrumento de 'cientificização' dos currículos escolares, passando a ser compreendida "como uma área de conhecimento dedicada à renovação da vida intelectual, à substituição do ensaísmo jurídico e literário pelo realismo científico” (MEUCCI, 2011, p. 57 apud OLIVEIRA, 2013), o que mantém e reforça o elitismo já relacionado a ela.

Em $1942^{6}$, com a Reforma Capanema, a Sociologia é novamente retirada dos currículos, entretanto, essa exclusão tinha menos a ver com uma função ideológica da disciplina do que com a indefinição do seu papel no contexto escolar (OLIVEIRA, 2013). Vale ressaltar que a ausência da disciplina não significa a ausência de seu ensino, tendo em vista que durante a Ditadura Militar o ensino de Sociologia apesar de não ser institucionalizado e obrigatório aparece atrelado à moral cívica. É somente em $1982^{7}$ que a Sociologia retorna aos currículos, neste momento sendo vinculada à ideia de formar os estudantes para a cidadania. Condição que é reforçada pela LDB (Lei 9.394/96) e se mantém até hoje nos textos oficiais, aparecendo de forma articulada para o ensino para o trabalho. A LDB/96 e o PNC/99

\footnotetext{
6 É retirada dos currículos pela Reforma Capanema (1942). A reforma estava preocupada em separar o ensino profissional do secundário, voltado para as elites, construindo um projeto pedagógico próprio para este segundo. Com isso, o ensino complementar que visava a preparação para as carreiras de ensino superior, em que a Sociologia estava inserida, é extinto.

7 A Lei $\mathrm{n}^{\circ}$ 7.044/82 institui o fim da profissionalização obrigatória, assim, surge a possibilidade de reintrodução de outras disciplinas nos currículos escolares, sendo uma a Sociologia uma dessas.
} 
(Parâmetros Nacionais Curriculares), ao colocarem a Sociologia como conhecimento apontavam para uma concepção transdisciplinar que negava e dificultava a consolidação da Sociologia como disciplina com uma finalidade própria no currículo escolar, uma vez que o ensino das temáticas referentes a ela poderia ocorrer de forma diluída nas outras disciplinas curriculares.

Sarandy (2004) argumenta que para entendermos o sentido da Sociologia enquanto disciplina curricular, devemos compreender quais os objetivos que se pretende atingir por meio dela, buscando qual a especificidade da disciplina para o Ensino Médio. Oliveira (2013) está preocupado com a discussão sobre a ontologia da disciplina justamente para compreender esse processo, argumentando que são apenas com as Orientações Curriculares Nacionais - OCN de 2006, seguida em 2008 da inclusão da disciplina como obrigatória, que um caráter afirmativo em relação ao ensino de Sociologia e ao sentido atribuído a ela aparece, isso ao ser relacionado ao processo de desnaturalização e estranhamento da realidade social, permitindo que a articulação de temas, teorias e conceitos sociológicos sejam operacionalizados para a compreensão da realidade social. Isso porque até então o sentido atribuído à Sociologia era flexibilizado a depender dos interesses momentâneos, sendo, inclusive, nas primeiras décadas de sua institucionalização atrelada aos regimes de governo autoritário e ao saber moral, voltados ainda para a formação das elites, sem qualquer ênfase nas suas potencialidades críticas (OLIVEIRA, 2013).

É nesse sentido, das contradições e das diversas significações envolvendo o ensino de Sociologia, que Oliveira (2013) argumenta que a Sociologia não é essencialmente crítica ou reflexiva. Com isso, ele não pretende negar esse potencial da disciplina, pelo contrário, pretende reforçar que o elemento crítico está na consolidação e legitimação da finalidade que ela assume nos 
currículos. Para ele, foi também essa instabilidade no currículo escolar que a prejudicou no processo de consolidação do seu objetivo específico, ou seja, da construção de um saber sociológico organizado e legitimado para o Ensino Médio, distinguindo-a das outras disciplinas de humanas e garantindo seu lugar nos currículos escolares.

Há certa unanimidade em se afirmar que a partir da década de 1950 ocorre uma significativa e importante mudança na compreensão da finalidade da Sociologia, inclusive quanto a relação entre o papel enquanto disciplina e o exercício da profissão, em que os sociólogos passam a reivindicar o lugar de cientistas especificamente treinados e formados para o exercício desta (SARANDY, 2004; COSTA, 2011; OLIVEIRA, 2013). Florestan Fernandes é um dos maiores responsáveis pela construção desse novo olhar neste momento, pois estava preocupado em legitimar a Sociologia como um dos meios de desenvolvimento social ou de formação do cidadão. A educação é defendida como fator de mudança social construtiva, isto é, tendente a realizar determinadas potencialidades inerentes aos requisitos mínimos do tipo de civilização urbana industrial instaurada no Brasil. O que nos interessa ressaltar é que neste momento Florestan defende a Sociologia no sentido de fomentar o espírito crítico e a reflexão autônoma dos indivíduos com base no conhecimento mais aprofundado dos determinantes e dinamismos da sociedade em contraposição às tendências de mercantilização do ensino (COSTA, 2011, p.42), aproximando a Sociologia do elemento da crítica social.

O desenvolvimento do pensamento crítico por meio do ensino de Sociologia se justifica, pois promoveria o contato do estudante com sua realidade, provocando o confronto com realidades distantes e culturalmente diferentes. Sarandy (2004) coloca que é nesse processo de distanciamento e aproximação que é possível desenvolver uma compreensão crítica sobre o mundo. Aqui, contrapõe-se a ênfase na utilidade profissional ou 
profissionalizante e a finalidade da disciplina, defende-se que adquirir uma visão sociológica do mundo ultrapassa a profissionalização, mesmo que

ajude neste processo. A Sociologia produz um olhar sobre o mundo, é a consolidação do que esse olhar tem de diferente dos demais e a importância dessa especificidade que defendemos aqui.

\section{A experiência escolar como prática reflexiva}

É justamente no olhar/ouvir/escrever treinado que está a especificidade da Sociologia, pois irá produzir nos alunos uma percepção sobre o mundo, constituindo "um prisma por meio do qual a realidade observada sofre um processo de refração" (OLIVEIRA, Roberto apud SARANDY, 2004). Isso significa que não são os conteúdos, suas temáticas e as teorias a grande especificidade das ciências sociais, tendo em vista que a história e a geografia também discorrem sobre as formas de ver o mundo e a sociedade, mas é justamente por apresentar "um olhar e um ouvir disciplinados pelo quadro teórico-conceitual e pela experiência em campo" (ZORZAL, Marta apud SARANDY, 2004) que a Sociologia constrói sua especificidade. Esse campo no Ensino Médio não se configura nos mesmos moldes do "ir a campo" na perspectiva acadêmica e de investigação, mas pelas reflexões sobre a própria realidade. Sarandy (2004) argumenta que a construção de competência (como prevê a PCN) a partir das ciências sociais se torna possível através dessa problematização e pelo confronto diante de realidades culturalmente diferentes, sendo por essa lógica que a noção de campo pode ser compreendida nesse eixo de ensino.

Com isso, mais do que revelar os problemas sociais, a Sociologia tem como finalidade o desenvolvimento de uma percepção sobre o mundo, a qual nós defendemos aqui que mais do que crítica e reflexiva, é participativa, pois pode e deve proporcionar aos estudantes a compreensão do lugar ativo e 
participativo que exercem na sociedade. As ocupações, em nossa perspectiva, colocam em prática a experiência escolar de forma política e ao chamar a atenção para o cotidiano da escola, evidenciam as disputas que regem esse ambiente, mais que isso, assumem um lugar nessa disputa. Um lugar de luta por reconhecimento enquanto atores na construção de sentidos e significados da escola. Em tempo de reformas autoritárias no sistema de ensino, a construção da Sociologia não pode deixar de assumir e tomar para si esse caráter reflexivo.

Nossa proposta reside nesta discussão acerca da potencialidade crítica da Sociologia no Ensino Médio, em que as ocupações aparecem nessa perspectiva como a materialização dessa possibilidade, não porque a disciplina tenha exercido uma função direta e explícita neste movimento, mas pela necessidade de construir e legitimar sua finalidade específica enquanto disciplina. Para tanto, nós vamos propor o vínculo entre a disciplina de Sociologia e as ocupações estudantis pela perspectiva da experiência escolar, a partir do conceito de experiência em Thompson (1981).

Exploramos, tanto na teoria como na prática, os conceitos de junção (como "necessidade", "classe" e "determinação"), pelos quais, através do termo ausente, "experiência", a estrutura é transmutada em processo, e o sujeito é reinserido na história. Ampliamos muito o conceito de classe, que os historiadores da tradição marxista empregam comumente - de maneira deliberada e não por uma "inocência" teórica - com uma flexibilidade e indeterminação desautorizadas tanto pelo marxismo como pela Sociologia ortodoxa. E quanto à "experiência" fomos levados a reexaminar todos os sistemas densos, complexos e elaborados pelos quais a vida familiar e social é estruturada e a consciência social encontra realização e expressão (sistemas que o próprio rigor da disciplina, em Ricardo ou no Marx de O Capital, visa excluir): parentesco, costumes, as regras visíveis e invisíveis da regulação social, hegemonia e deferência, formas simbólicas de dominação e de resistência, fé religiosa e impulsos milenaristas, maneiras, leis, instituições e ideologias - tudo o que, em sua totalidade, compreende a "genética" de todo processo histórico, sistemas que se reúnem todos, num certo ponto, na experiência humana comum, que exerce ela própria (como experiências de classe peculiares) sua pressão sobre o conjunto (THOMPSON, 1981, p. 188-189). 
Os estudantes afirmam que ocuparam seus colégios porque não se sentem reconhecidos como sujeitos ativos em seu processo educativo. A experiência escolar, já anterior às ocupações, pode ser analisada, com base nesta identificação dos próprios ocupantes e com base na proposta de Thompson (1981), como um processo negativo.

Para os estudantes as propostas foram o estopim de uma insatisfação que já fazia parte de suas trajetórias escolares. A escola, que já era vivida (THOMPSON, 1981) como um lugar frio e hierarquizado, onde eles não eram vistos, com as medidas governamentais estava ameaçada de se tornar ainda pior.

não... eu nunca senti acolhida pela escola antes da ocupação. Nunca. Nunca. Nunca. Eu acho que em escola nenhuma que eu estudei. Não... na escola que eu estudei até a quarta série eu gostava. [risos coletivos] Mas antes, nem na biblioteca... sei lá.... lugar nenhum... muita frieza... eu sempre digo que a escola é fria... no sentido dela ser gelada, porque é muito frio mesmo e encana muito frio na escola, mas é tipo... eu acho que ela é fria em todos os sentidos. (Estudante 03 , aluna do $3^{\circ}$ ano do EM, entrevista 2, grifos nossos)

é uma coisa torturante [em relação às cores claras e pálidas da escola]. Eu me sinto muito presa naquela escola. E na hora do intervalo, quando a gente sair, volte e meia eu falo: "nossa, é os presidiários indo tomar banho de sol" (Estudante 05, aluna $3^{\circ}$ ano do EM, entrevista 2).

A ênfase nas experiências de desrespeito busca evidenciar que sentimentos morais de injustiça funcionam como propulsores das lutas sociais, ampliando as análises do porque os movimentos surgem (HONNETH, 2003). A narrativa dos estudantes em relação à instituição pode ser compreendida a partir dessa gramática moral proposta por Honneth. Materializada na figura dos professores, a relação com a escola é marcada pelo sentimento de indiferença, não é à toa que aqueles que demonstram preocupação com os estudantes para além da mera transmissão de 
conteúdo são colocados como excepcionais. Na fala dos alunos, é recorrente o elogio a um professor específico, tanto quando eram questionados sobre o que é ser um bom professor quanto sobre a escola ideal ou ainda sobre a sociabilidade durantes e depois das ocupações, e em todos os casos era a forma como a relação entre eles era estabelecida o elemento de diferenciação: “ele se importa com a gente como humano mesmo, sabe?" (Estudante 07, aluno 2o ano do EM, entrevista 3). A proximidade aparece como fator importante na configuração do 'bom professor', a atitude de se colocar na mesma hierarquia do estudante é vista como carinho e reconhecimento do potencial do aluno. O mesmo aluno comenta "Eu comecei a perceber mais os professores como humanos, não só como tipo, ah... eu vou pôr eles num pedestal e não vou poder tocá-los. O professor ele veio, ele desceu e ficou do nosso lado e falou não" e em outro trecho acrescenta, "ele não te vê como um aluno que não sabe de nada, que ainda vai passar por tudo que ele já passou. Ele te vê como uma pessoa que tem um potencial muito grande”.

Com isso, a afetividade, entendida aqui como o "conversar com o aluno" e "fazer mais do que passar a matéria no quadro", aparece como um componente de qualificação do professor e da disciplina, sendo a falta desta um elemento com potencial normativo. O que significa que o sentimento de indiferença vivenciado pelos estudantes por parte da instituição escolar ao ser atrelado à quebra de expectativas morais de direito e estima, representadas tanto pela ausência de diálogo frente a PEC e a MP 746 quanto na ausência de reconhecimento dos estudantes enquanto sujeitos ativos nas escolas, impulsiona a emersão dos movimentos de ocupações. É nesse sentido que a "voz", ou melhor, a ausência dela, aparece como um elemento retratando essa relação. 
vamos lutar contra a MP, eu estou falando dentro da escola, a gente deu voz pros alunos e isso é uma coisa muito importante, no Barão o aluno é cortado. $\mathrm{O}$ aluno que falar alguma coisa, não. $\mathrm{O}$ aluno quer fazer alguma coisa, não. Você não pode, você não tem direito, você não tem voz, independente de ter grêmio ou não. Eu estudo lá a anos eu sei muito bem disso. Tipo, muito bem disso. (Estudante 06, aluna 2ㅜa ano EM, entrevista 3)

Sim, exato! Exatamente... tipo, pra eles, não importam o que a gente está pensando, pra eles não importa o que eu vou comer, pra eles não importa aonde eu vou dormir... só importa o deles. Eu sei porque eu já passei por muita coisa difícil, realmente... e sempre vi que... a política, a nossa política não está totalmente do nosso lado. Então você vê que... você precisa de mais voz. (Estudante 02, aluno 1ㅜa ano do EM, entrevista 1)

Para Honneth (2003), é a percepção coletiva dessas experiências de sofrimento, o que ele chama de semântica coletiva, que interferem na motivação dos sujeitos para que eles se engajem em lutas sociais. As ocupações foram mobilizadas, assim, pela necessidade de reconhecimento dos estudantes como atores importantes no que tange às decisões em relação ao cotidiano da escola, o que aparece nas entrevistas pela representação da voz (HONNETH, 2003).

A Sociologia surge nesse contexto, nas falas dos próprios alunos, como uma disciplina que te faz pensar sobre a sociedade. Ao defender diretamente a permanência das disciplinas de Sociologia e filosofia no Ensino Médio, um dos alunos atribui a essas disciplinas a finalidade de "introduzir à dúvida", com a função de questionar os padrões e condições sociais estabelecidos.

[...] E uma coisa que, acho que talvez, o que mais me incomoda na MP é o fato de ela tirar Sociologia e filosofia, que eu entendo que assim... eu sempre falei isso, antes, durante e depois, e acho que tipo vou tatuar na minha testa, porque tipo assim Sociologia e filosofia te introduz a dúvida, como nosso professor de Sociologia já comentou, sabe. Sociologia como o próprio nome já diz, é o estudo da sociedade, então, você duvida da sociedade (Estudante 07 - aluno 2o ano do EM, entrevista 3 ). 
Outra aluna defende que "É a única coisa que eu acho que a gente leva mesmo pra vida" (Estudante o3, aluno do $3^{\circ}$ ano do EM, entrevista 2) e a colega acrescenta justificando a razão disso "porque a gente aprende mesmo a pensar (Estudante 05, aluno do $3^{\circ}$ ano do EM, entrevista 2). É nesse sentido, dos próprios alunos atribuírem à Sociologia a reflexão sobre a sociedade, que defendemos o movimento das ocupações como resultado da reflexividade desses alunos sobre a própria condição escolar.

\section{Considerações Finais}

As reflexões trazidas neste trabalho não tinham a pretensão de ser conclusivas, no sentido de provar uma hipótese ou teoria, mas de discutir os sentidos que o movimento de ocupações escolares pode assumir nesse contexto de reforma no sistema de ensino brasileiro. Um dos nossos objetivos era propor a discussão sobre a experiência escolar enquanto potencial elemento político no desenvolvimento desses sujeitos. Analisamos, assim, as ocupações como um processo de formação dos estudantes enquanto um grupo político, que se mobilizou com base em uma análise crítica da estrutura escolar e contrária à proposta governamental de reforma do Ensino Médio. Podemos identificar este processo de mobilização estudantil, neste sentido, como uma análise reflexiva dos próprios estudantes acerca de sua escolarização.

Evidenciamos ainda o discurso dos próprios ocupantes, que afirmam que para além da falta de consulta governamental acerca da reforma, um dos motivos de maior insatisfação deles é a retirada da Sociologia como disciplina obrigatória, que passa a compor um dos eixos optativos do Ensino Médio, como evidencia a BNCC/2017. 
A Sociologia, como demonstrado anteriormente, tem um histórico de intermitência no ensino brasileiro e está novamente em um processo de marginalização. A ênfase na necessidade em reivindicar seu papel crítico e reflexivo, é, portanto, nosso objetivo ao traçar esta análise, fazendo coro à reivindicação dos ocupantes acerca da necessidade de construção do espaço escolar participativo, pautado na experiência ativa, na valorização e reconhecimento daqueles que o vivenciam.

\section{REFERÊNCIAS}

BRASIL. Lei no 12.061, de 27 de outubro de 2009. Altera o inciso II do art. 40 e o inciso VI do art. 10 da Lei no 9.394, de 20 de dezembro de 1996, para assegurar o acesso de todos os interessados ao Ensino Médio público. Diário Oficial da União. Brasília, DF, 28 de outubro de 2009, Seção 1, p. 1. Disponível em: < https://goo.gl/mXzH8s>. Acesso em: 16 nov. 2017.

BRASIL. Lei no. 13.005, de 25 de junho de 2014. Aprova o Plano Nacional de Educação - PNE. Diário Oficial da União. Brasília, DF, 26 de junho de 2014, Seção 1, Ed. Extra, p. 1. Disponível em: < https://goo.gl/7yEiNE>. Acesso em: 12 jan. 2018.

BRASIL. Medida Provisória № 746, de 22 de setembro de 2016. Diário Oficial da União, Brasília, DF, 23 de setembro de 2016, Seção 1, Ed. Extra, p.

1. Disponível em: < https://goo.gl/kFbydı. Acesso em: 26 mar. 2017.

BRASIL. Ministério da Educação. Instituto Nacional de Estudos e Pesquisas Educacionais Anísio Teixeira (INEP). Censo Escolar 2017: Notas Estatísticas. Brasília, DF, 2018. 21 p. Disponível em: < https://goo.gl/95bZFG>. Acesso em: 31 jan. 2018.

BRASIL. Ministério da Educação (MEC). Planejando a Próxima Década: Conhecendo as 20 Metas do Plano Nacional de Educação. Brasília, DF, 2014. Disponível em: <https://goo.gl/51t1AE>. Acesso em: 14 ago. 2017. 
BRASIL. Presidência da República Casa Civil. Constituição da República Federativa do Brasil de 1988. Diário Oficial da União, Brasília, DF, 5 de outubro de 1988, Seção 1, p. 1. Disponível em: <http://www.planalto.gov.br/Ccivil_03/leis/L8069.htm>. Acesso em: 12 mar. 2018.

COSTA, Diogo Valença de Azevedo. Florestan Fernandes e o ensino da Sociologia na escola média brasileira. Revista inter-legere. $n^{\circ} 09$, jul/dez de 2011. p.40/6o

HONNETH, A. Luta por reconhecimento: A gramática moral dos conflitos sociais. São Paulo: Editora 34, 2003. 296 p.

OLIVEIRA, Amurabi. Revisitando a história do ensino de Sociologia na Educação Básica. Acta Scientiarum. UEM. v.35, n.2, jul./dec. 2013. p. 179189

PACHECO, C. Ocupar e resistir: as ocupações das escolas públicas como parte do ciclo atual de mobilização juvenil no Brasil. 2018. Dissertação (Mestrado em Sociologia) - Departamento de Ciências Sociais, Universidade Federal do Paraná, Curitiba.

SARANDY, F. Reflexões acerca do ensino de Sociologia do Ensino Médio. IN: CARVALHO, Lejeune Mato grosso de. Sociologia em Debate: Experiência e discussão de Sociologia no Ensino Médio. Ijuí: Ed. Unijuí, 2004 .

THOMPSON, E. O termo ausente: experiência. In: A miséria da teoria ou um planetário de erros: uma crítica ao pensamento de Althusser. Rio de Janeiro: Zahar, 1981. p.180-200. 